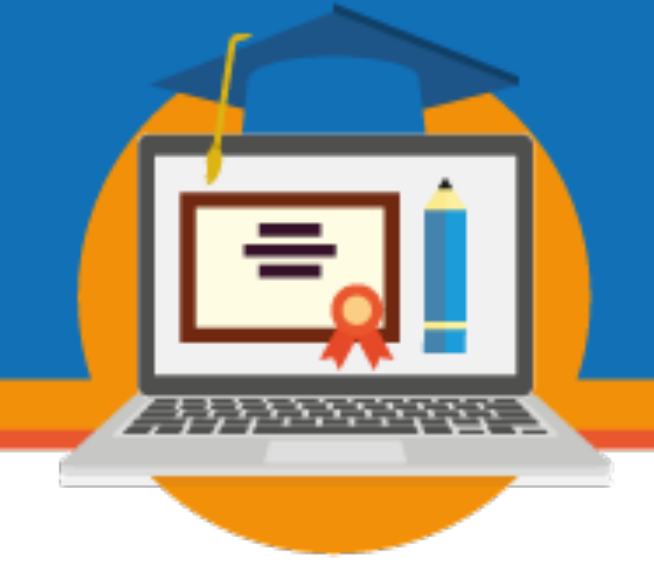

\title{
A EVASÃO EM CURSOS SUPERIORES A DISTÂNCIA: UM ESTUDO ACERCA DE FATORES QUE INTERFEREM NA PERMANÊNCIA DOS ESTUDANTES
}

\author{
Danielle Xabregas Pamplona Nogueira \\ Universidade de Brasília \\ danielle.pamplona@gmail.com
}

Marcello Ferreira

Universidade de Brasília marcellof@unb.br

\author{
Helena Célia de Souza Sacerdote \\ Universidade de Brasília \\ helenasacerdote@gmail.com \\ Natália Rodrigues Faria \\ Universidade de Brasília \\ nataliarf84@gmail.com \\ Bárbara Beatriz da Silva \\ Universidade de Brasília \\ barbarabeatrizdasilva6@gmail.com
}

Kharolinne Miguel de Souza

Universidade de Brasília kharoll37@gmail.com

Eixo 1: Política, gestão e financiamento da educação a distância

Resumo: Esse estudo objetiva identificar fatores que levam à evasão em cursos de graduação na modalidade a distância. Para isso, foi realizado um levantamento de artigos disponibilizados no Portal de Periódicos da Capes (https://www.periodicos.capes.gov.br/) que tratam da temática da evasão em cursos de graduação a distância, publicados entre 2014 e 2019. Foi aplicado o método de análise de conteúdo (AC), com o uso do software Iramuteq. O corpus geral foi constituído por 23 textos, separados em parágrafos. Disso, o software considerou 10 textos, 1.597 ocorrências, sendo 578 formas e 399 hapax. Foram utilizadas a lematização e todos os parâmetros-chaves. Os resultados sugerem que os principais fatores que interferem na permanência dos estudantes no ensino superior são os fatores pessoais ou individuais, como dificuldade de adaptação à modalidade e falta de domínio da tecnologia etc.; e institucionais, 




como falta de apoio ao aluno, insatisfação com o desempenho dos tutores e falta de incentivo da instituição, corroborando com o que é encontrado na literatura a respeito do assunto. Conclui-se que ambos os fatores possuem interferência semelhante no processo de evasão desse público.

Palavras-chave: Evasão; Educação a Distância; Fatores.

\section{Introdução}

As políticas de democratização da educação superior no Brasil têm proporcionado mais acesso a esse nível educacional, sobretudo a partir do movimento de expansão iniciado na década de 1990. No entanto, segundo Lozzi (2019) essa democratização não se restringe ao acesso - antes, contempla a permanência dos estudantes até a conclusão de seus cursos, com qualidade. Nesse sentido, cabe analisar o processo de expansão da educação superior a distância, tanto na dimensão acesso quanto conclusão dos cursos.

O Censo da Educação Superior 2018 (Inep, 2018) demonstrou que a participação percentual dos ingressantes em cursos de graduação a distância em 2008 era de 19,8\%. Em 2018, essa participação foi para quase 40\%. No mesmo período, o número de ingressos variou 10,6\% nos cursos de graduação presencial e triplicou $(196,6 \%)$ nos cursos a distância. Ao mesmo tempo, dados obtidos em estudo desenvolvido por Silva Filho (2017) demonstraram que a tendência de evasão, especialmente na modalidade a distância, é crescente nos diversos tipos de curso. 


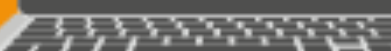

\begin{tabular}{|c|c|c|c|c|c|c|}
\hline & $2011 / 2012$ & $2012 / 2013$ & $2013 / 2014$ & $2014 / 2015$ & Media & Tendência \\
\hline Bacharelado & $23 \%$ & $22 \%$ & $22 \%$ & $22 \%$ & $22 \%$ & estável \\
\hline Distância & $28 \%$ & $34 \%$ & $35 \%$ & $39 \%$ & $34 \%$ & crescente \\
\hline Pública & $31 \%$ & $36 \%$ & $37 \%$ & $41 \%$ & $36 \%$ & estável \\
\hline Privada & $12 \%$ & $15 \%$ & $19 \%$ & $16 \%$ & $16 \%$ & estável \\
\hline Presencial & $22 \%$ & $21 \%$ & $21 \%$ & $21 \%$ & $21 \%$ & estável \\
\hline Pública & $24 \%$ & $23 \%$ & $24 \%$ & $23 \%$ & $24 \%$ & estável \\
\hline Privada & $17 \%$ & $13 \%$ & $13 \%$ & $12 \%$ & $14 \%$ & estável \\
\hline Licenciatura & $22 \%$ & $21 \%$ & $23 \%$ & $25 \%$ & $23 \%$ & estável \\
\hline Distância & $25 \%$ & $24 \%$ & $31 \%$ & $33 \%$ & $28 \%$ & crescente \\
\hline Pública & $27 \%$ & $26 \%$ & $20 \%$ & $40 \%$ & $28 \%$ & oscilante \\
\hline Privada & $20 \%$ & $18 \%$ & $22 \%$ & $21 \%$ & $20 \%$ & crescente \\
\hline Presencial & $20 \%$ & $19 \%$ & $20 \%$ & $20 \%$ & $20 \%$ & estável \\
\hline Pública & $23 \%$ & $23 \%$ & $25 \%$ & $23 \%$ & $24 \%$ & estável \\
\hline Privada & $18 \%$ & $16 \%$ & $15 \%$ & $16 \%$ & $16 \%$ & estável \\
\hline & & & & & & \\
\hline Tecnólogo & $42 \%$ & $37 \%$ & $43 \%$ & $40 \%$ & $41 \%$ & estável \\
\hline Distância & $49 \%$ & $41 \%$ & $51 \%$ & $49 \%$ & $48 \%$ & estável \\
\hline Pública & $50 \%$ & $42 \%$ & $52 \%$ & $50 \%$ & $48 \%$ & estável \\
\hline Privada & $36 \%$ & $34 \%$ & $28 \%$ & $26 \%$ & $31 \%$ & decrescente \\
\hline Presencial & $40 \%$ & $35 \%$ & $38 \%$ & $34 \%$ & $37 \%$ & oscilante \\
\hline Pública & $43 \%$ & $38 \%$ & $41 \%$ & $36 \%$ & $39 \%$ & oscilante \\
\hline $\begin{array}{l}\text { Privada } \\
\end{array}$ & $27 \%$ & $25 \%$ & $25 \%$ & $29 \%$ & $27 \%$ & estável \\
\hline
\end{tabular}

Fonte: Silva Filho (2017).

Considerando o cenário em tela, este estudo tem como objetivo identificar fatores que levam à evasão em cursos de graduação na modalidade a distância. Para isso, foi realizado um levantamento de artigos disponibilizados no Portal de Periódicos da Capes (https://www.periodicos.capes.gov.br/) que tratam da temática da evasão em cursos de graduação a distância, publicados entre 2014 e 2019.

\section{Revisão da Literatura}

A literatura a respeito da evasão em cursos a distância aponta para uma compreensão convergente de que esse fenômeno é multidimensional. Tinto (1975), por exemplo, explica o

\section{SEMINÁRIO DE EDUCAÇÃO A DISTÂNCIA}

Diálogos sobre EaD e uso das TDIC na educação: regulamentação em tempos recentes 


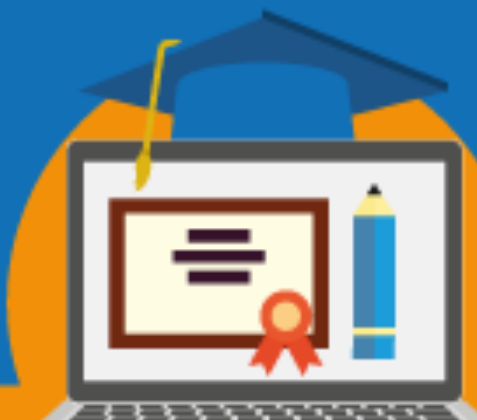

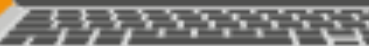


processo de evasão considerando três modelos teóricos. O primeiro modelo analisa as características dos próprios estudantes que se relacionam à sua persistência nos cursos. $\mathrm{O}$ segundo modelo analisa a interação desse estudante com ambiente acadêmico. $\mathrm{O}$ terceiro modelo, por sua vez, analisa as características das instituições de ensino superior que influenciam o processo de evasão do estudante.

O estudo de Lee e Choi (2011) levantou 69 fatores que influenciam na evasão. Esses fatores foram, também, classificados em três categorias: (a) fatores do estudante, (b) fatores do curso/programa, e (c) fatores ambientais. Dessas categorias, a de maior expressão foi a relacionada aos fatores, a saber: experiências acadêmicas anteriores, experiências relevantes, competências relevantes e atributos psicológicos. Os fatores referentes ao Curso / Programa foram identificados como: design, suportes institucionais e interações. Já os fatores ambientais, incluem compromissos de trabalho, várias responsabilidades familiares e sociais, e apoio insuficiente da família, amigos ou colegas.

Sousa e Maciel (2016) concluem que a evasão se materializa devido ao conjunto de fatores que envolvem a relação sociocultural, as instituições de ensino superior (IES), o curso e o estudante. Por isso, consideram que evasão não pode mais ser justificada somente pelas opções pessoais dos estudantes, posto que, muitos elementos que determinam essa evasão são, também, confundidos com as dificuldades específicas da modalidade a distância.

Com o olhar específico para o estudante, Carneiro, Ferreira e Moura (2019) compararam características dos traços de personalidade dos discentes que persistem em cursos EaD. Os autores entendem que há relação entre os fenômenos de evasão e persistência. Para eles, a persistência pode ser analisada a partir de comportamentos para a intenção de aprendizagem e conclusão dos cursos. Sendo assim, os resultados mostram que características relacionadas ao gênero, estado civil, renda e área de conhecimento dos cursos apresentam diferentes comportamentos de persistência em cursos a distância.

A partir desses autores, esse estudo compreende que os fatores que levam à evasão na educação a distância podem ser classificados como fatores pessoais e fatores institucionais. 


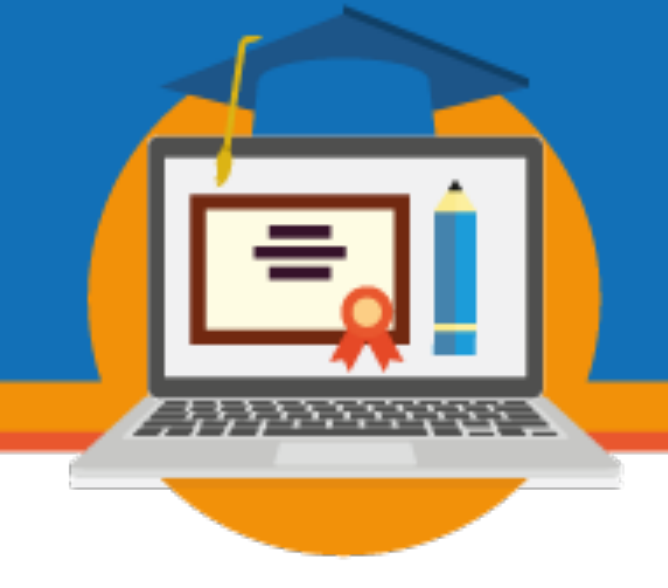

\section{Metodologia}

O objetivo deste relatório diz respeito à análise de 23 materiais relativos às publicações acadêmicas (artigos) acerca de evasão na educação a distância, disponíveis no Portal de Periódicos da Capes, publicados no período entre 2014 e 2019.

Inicialmente, foram utilizados na busca os descritores evasão AND educação a distância, para os quais foram localizadas 102 produções acadêmicas. Nessas produções, foi aplicado um filtro para selecionar somente aquelas aplicadas à educação superior e que fossem artigos, chegando ao corpus desse estudo. Depois da leitura dos textos, foi elaborada uma planilha síntese das publicações, indicando objetivo dos estudos, conceitos de evasão e fatores de evasão

Em seguida, foi aplicado o método de análise de conteúdo (AC), com o uso do software IRaMuTeQ. O corpus geral foi constituído por 23 textos, separados em parágrafos. Disso, o software considerou 10 textos, 1.597 ocorrências, sendo 578 formas e 399 hapax. Foram utilizadas a lematização e todos os parâmetros-chaves (ou formas, como substantivos, verbos, adjetivos etc.).

$\mathrm{Na}$ análise de conteúdo, foram, ainda, realizadas Análise Fatorial de Correspondência (AFC), Classificação Hierárquica Descendente (CHD) e Análise de Similitude.

\section{Resultados}

A Análise Fatorial de Correspondência (AFC) associa textos com variáveis e, em uma representação gráfica dos dados, ajuda a visualização da proximidade entre classes ou palavras. Os textos (identificados como “itens”) 8, 9,10 e 4 aparecem como mais significativos devido à localização deles no plano fatorial. O tema aponta para cursos de educação a distância e fatores de evasão. Apenas em uma inspeção visual rápida, percebe-se que o estudante tem como principal dificuldade, que o leva à evasão, a falta de tempo para se dedicar aos estudos,

\section{SEMINÁRIO DE EDUCAÇÃO A DISTÂNCIA}




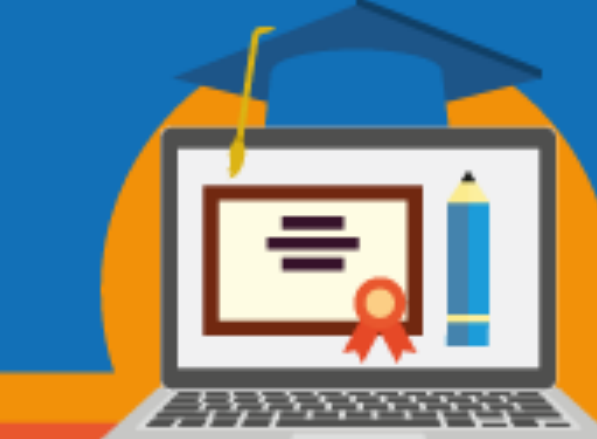

conforme se observa na Figura 1. No entanto, é preciso analisar os dados mais profundamente para confirmar esses resultados preliminares.

Figura 1 - AFC

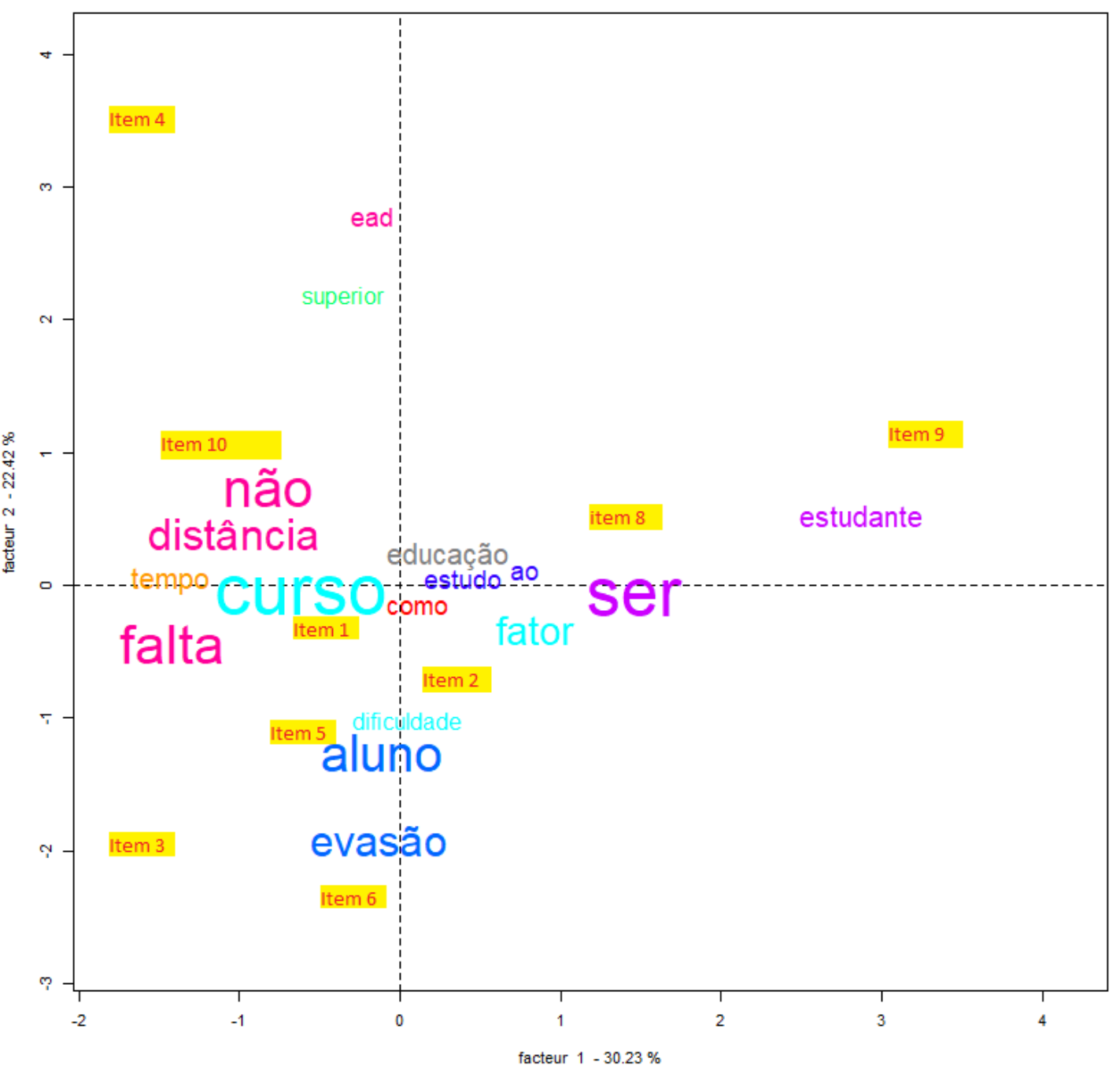




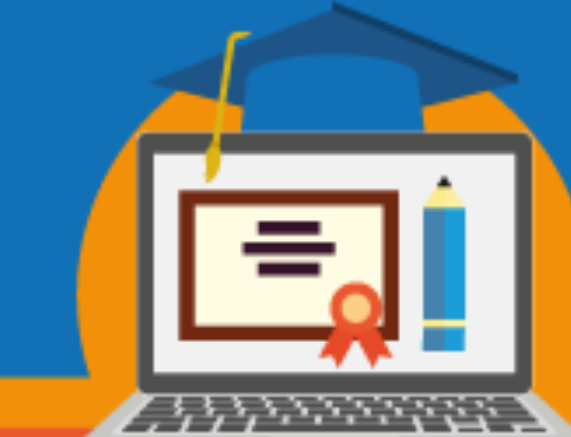

A CHD se baseia na proximidade léxica e na ideia de que palavras usadas em contexto similar estão associadas ao mesmo mundo léxico. Considerando que a análise foi realizada sobre parágrafos, o software dividiu o corpus em 36 deles.

O corpus total em análise está ilustrado no dendrograma da Figura 2. Ele foi dividido em quatro classes e em duas ramificações principais: A (fatores de evasão) e B (sucesso em EAD).

Figura $2-\mathrm{CHD}$

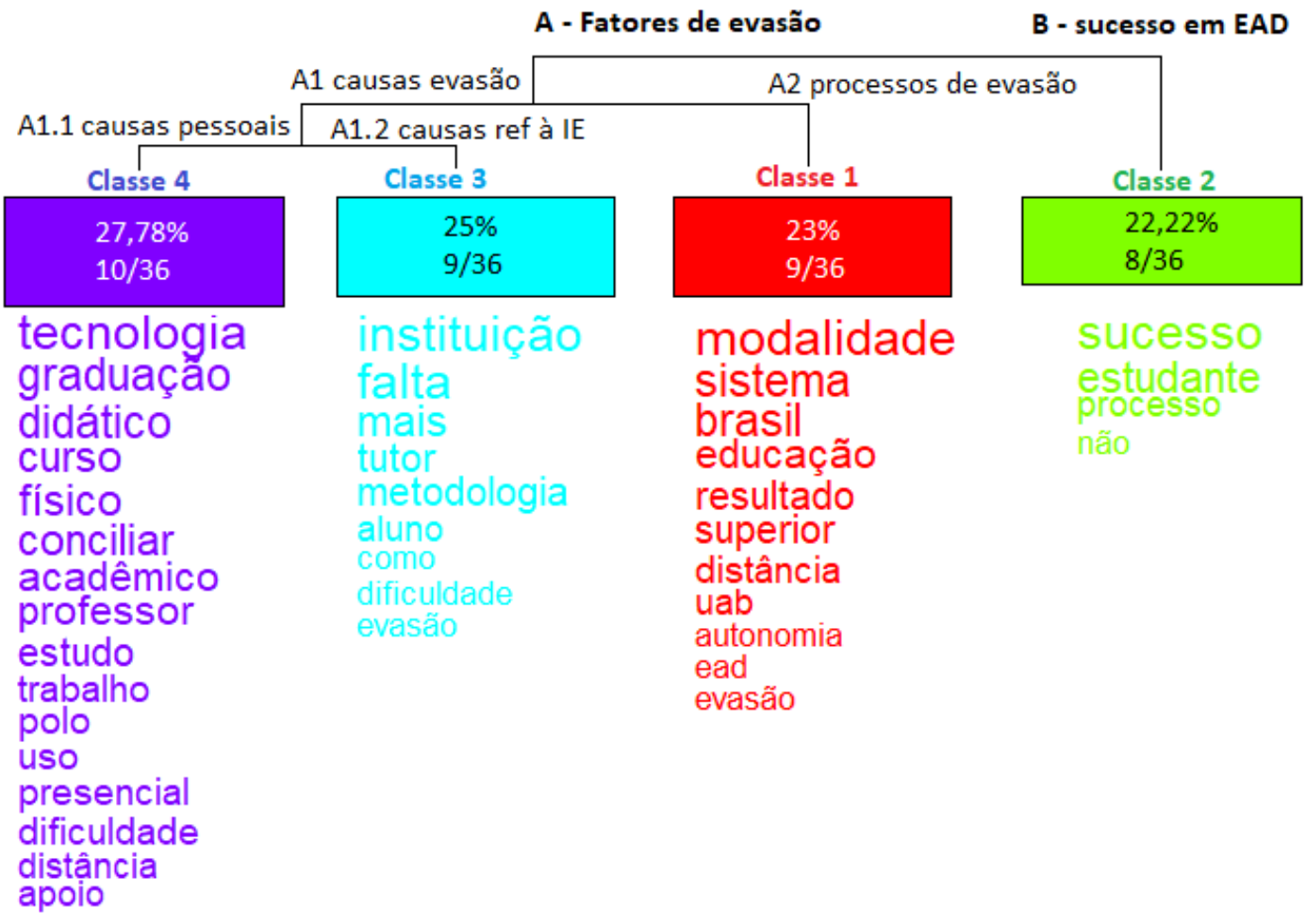

A ramificação A é formada por subdivisões: A1 (causas evasão) e A2 (processos de evasão). A ramificação A1 ainda se subdivide em A1.1 (causas pessoais) e A1.2 (causas referentes à IES). A ramificação A2 é formada pela Classe 1.

A ramificação A1 engloba as causas da evasão enquanto suas subdivisões, A1.1 e A1.2, em causas pessoais e causas referentes à instituição de ensino, respectivamente. Juntas elas 


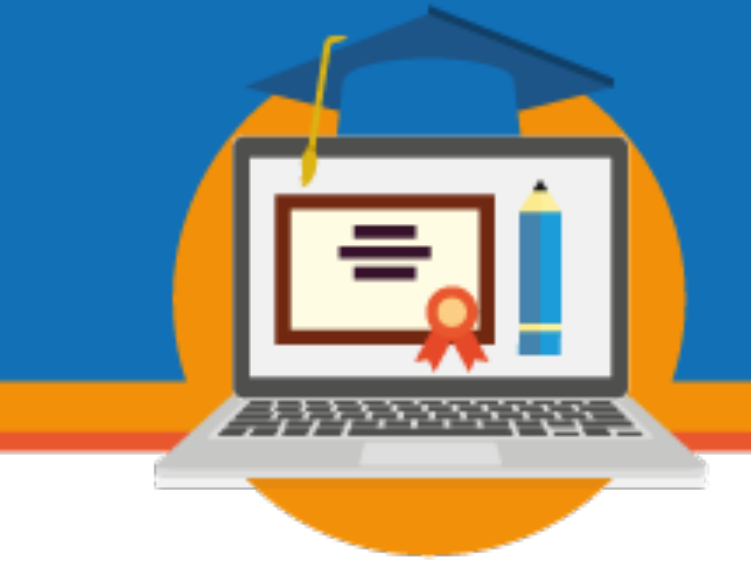

representam mais da metade do corpus $(27,78 \%$ e $25 \%$ e 10 e $9 / 36)$, portanto é a mais representativa em relação ao corpus.

Os textos mais significativos da ramificação A1.1 (Classe 4) engloba 10 de 36 parágrafos, em 27,78\% e focaliza as causas dos processos de evasão. Alguns trechos de maiores scores estão descritos a seguir.

as questões relacionadas ao ensino e de responsabilidade da instituição ministrante como estrutura física tecnológica metodológica professores tutores material didático e outras considerou se estrutura de ensino as questões relacionadas ao aluno em termos de deficiência de conteúdo como pré requisitos para as disciplinas da graduação de habilidade técnica para o uso e aproveitamento das tecnologias e das mídias para a ead de disponibilidade de equipamentos tecnológicos particulares adequados às necessidades e às questões que interferem na sua autonomia como aluno da ead considerou se estrutura de aprendizagem os fatores considerados de influência na evasão dos alunos não concluintes não dispunha de internet em casa falta de interação e diálogo com professor e tutor a distância deficiência de conteúdo da educação básica para a superior acreditou ser mais fácil fazer uma graduação a distância problemas com a internet no polo ausência do material impresso ou de difícil compreensão não era o curso que desejava realizar decidiu realizar o curso porque não tinha outra opção sensação de abandono pela instituição ministrante do curso dificuldade quanto ao conhecimento de informática não dispunha de computador em casa não fez curso de informática antes de iniciar a graduação falta de identificação com o curso falta de conhecimento de informática deficiência de conteúdo da educação básica para a superior problemas particulares e de saúde conexão de internet precária e lenta não havia com quem sanar as dúvidas tutoria presencial não prestava o apoio necessário falta de mercado de trabalho para o curso falta de feedback das correções avaliações e exercícios não conseguir conciliar o tempo com o grupo de estudo falta de interação e diálogo com o professor e tutor a distância falta de tempo para estudo problemas pessoais com o tutor presencial (Item_10 score : 119.09

a falta de domínio da tecnologia diferentes espaços tempos ou a falta da figura física do professor a não adequação do tempo para seus estudos nesse caso as participações irregulares nos ambientes virtuais de aprendizagem o estudo conciliado com o trabalho falta de tempo para a vida social e em seu lar provoca desconforto no educando não direciona um tempo apropriado em seu perfil profissional ou pessoal levando o à desistência do curso embora obtenha notas razoáveis tyler smith 2006 outro aspecto é a diferença espaço tempo que pode levar ao sentimento de solidão na educação a distância em que o acadêmico sem a autonomia necessária para superar esses paradigmas pode não concluir sua graduação maia mattar (Item_01 *Ano_2014 score : 89.42)

Os textos mais significativos da ramificação A1.2 (Classe 3) engloba 9 de 36 parágrafos, em $25 \%$ e focaliza as causas dos processos de evasão no que diz respeito às instituições de ensino. Alguns trechos de maiores scores estão descritos a seguir. 


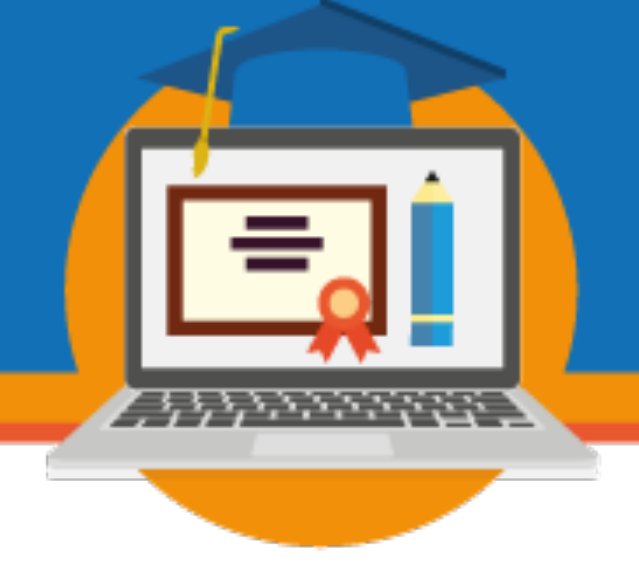

"superior"; o nó "curso" ligado a "aluno". Desse modo, infere-se que o tema diz respeito à evasão dos cursos a distância.

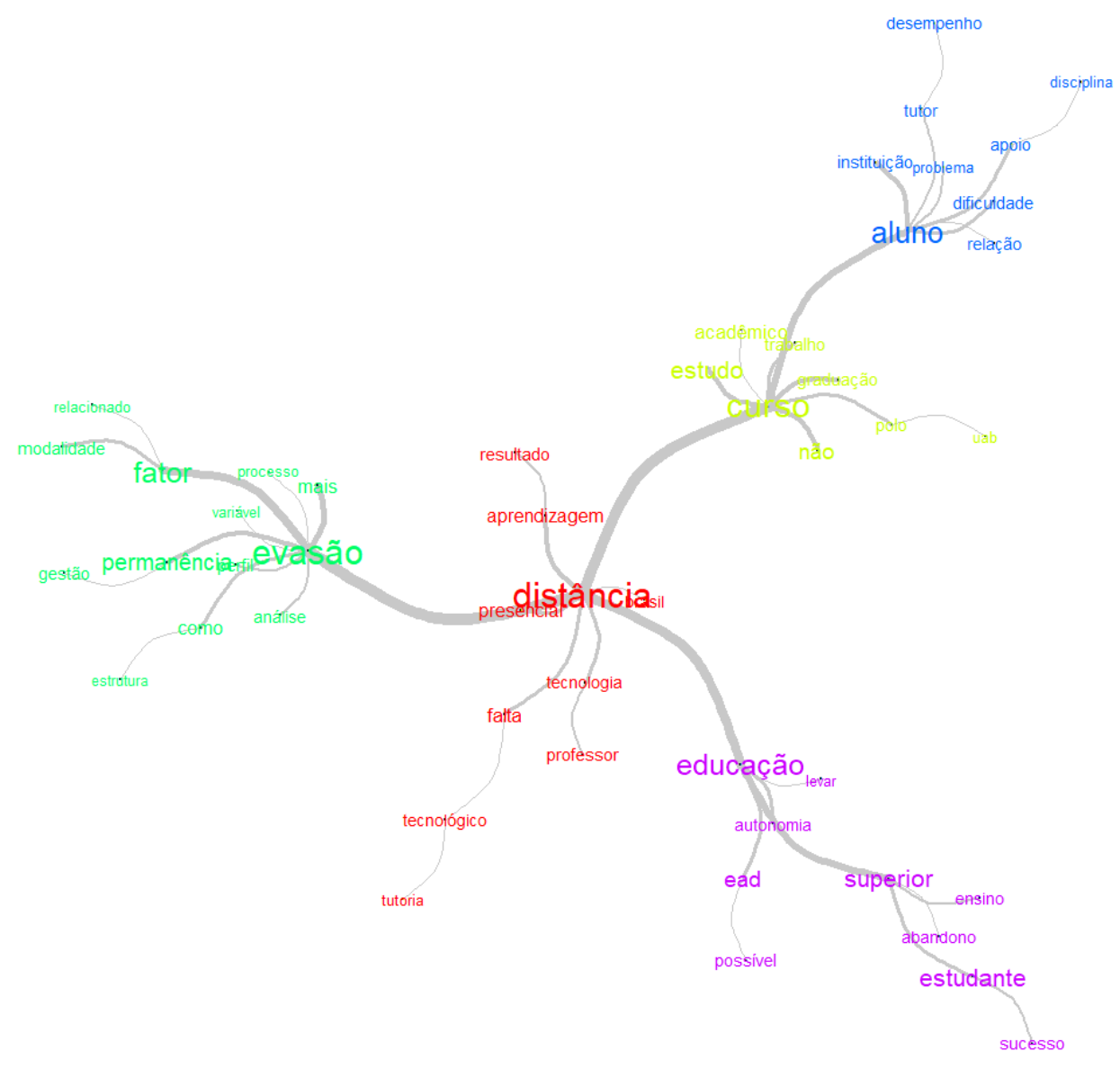

Portanto, os dados apresentados corroboram a literatura ao evidenciar os fatores pessoais e os institucionais como predominantes na evasão dos estudantes de cursos superiores a distância. Desses fatores, destacam-se mais os fatores pessoais, os quais estão relacionados a: dificuldade de adaptação à modalidade, falta de domínio da tecnologia, falta de acesso à internet, indisponibilidade de computador, sentimento de não acolhimento por parte da IES, distância do polo presencial, falta de identificação com o curso, falta de conhecimento de

\section{SEMINÁRIO DE EDUCAÇÃO A DISTÂNCIA}

Diálogos sobre EaD e uso das TDIC na educação: regulamentação em tempos recentes 3 a 6 de novembro de 2020 - Brasília/DF - Online 


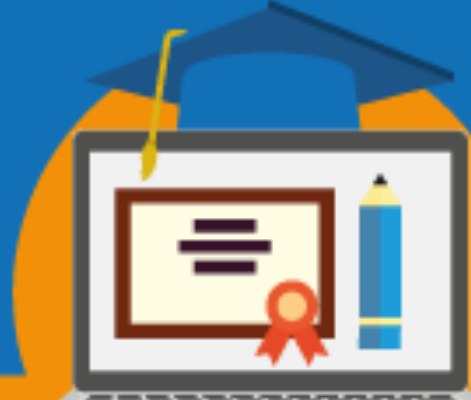

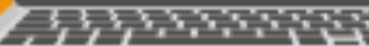

informática, deficiência de conteúdo da educação básica para a superior, dificuldades financeiras, falta de mercado de trabalho para o curso e não conseguir conciliar o tempo com os estudos. Em seguida, foram evidenciados os fatores institucionais, a saber: a falta de apoio ao aluno, insatisfação com o desempenho dos tutores e falta de incentivo da instituição.

\section{Considerações Finais}

O presente estudo teve como objetivo o de identificar fatores que levam à evasão em cursos de graduação na modalidade a distância. A partir dos dados levantados, conclui-se que fatores que levam à evasão são de ordem pessoais e institucionais, sendo os primeiros, em maior evidência'. No entanto, ao ser analisada a relação entre esses fatores, conclui-se, ainda, que os fatores pessoais são potencializados pelos fatores institucionais. Exemplo disso está na relação entre a dificuldade de adaptação à modalidade, por parte do estudante, e a falta de apoio ao estudante, por parte da instituição.

Dessa forma, espera-se que esse estudo possa contribuir para o debate sobre a evasão, no âmbito de políticas institucionais, as quais devem reconhecer, cada vez, as características dos estudantes a distância, pois características individuais desfavoráveis podem ser reforçadas por dificuldades ou inadequações institucionais.

1 Tendo em vista a sutileza dessa preponderância, do ponto-de-vista estatístico, é oportuno que outros estudos investiguem mais profundamente a visão do aluno em relação às expectativas mantidas em relação a uma IES que ofereça cursos EaD. 


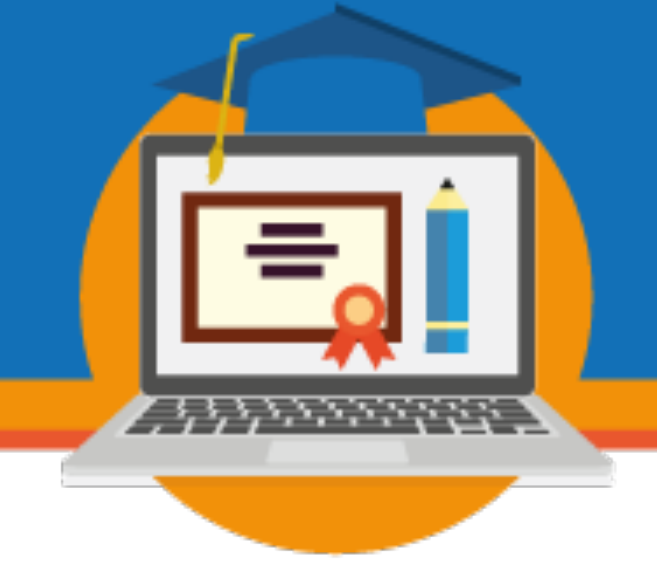

\section{Referências}

CARNEIRO, T. C. J.; FERREIRA, M.; MOURA, R. L. Traços de personalidade e persistência discente em cursos superiores na modalidade a distância. Revista Diálogo Educacional, Curitiba, v. 19, n. 60, p. 137-172, jan./mar. 2019.

LOZZI, S. P., NOGUEIRA, D. X. P., MOREIRA; A. M. A., SANTOS, C. A. As políticas de cotas na Universidade de Brasília: da luta pelo direito à educação à democratização do acesso. In SOUSA, A. S. Q., MACIEL, C. E. M. (Org.). Desafios na Educação Superior: acesso, permanência e inclusão. Curitiba: CRV, 2019. p. 95-116.

TINTO, V. Dropout from higher education: a theoretical synthesis of recente research. Review of Educational Research, v. 45, n. 1, p. 89-125, 1975.

SILVA FILHO, R. L. L. A evasão no ensino superior brasileiro: novos dados. In:Instituto Lobo, out, 2017. Disponível em: http://www.institutolobo.org.br/

imagens/pdf/artigos/art_088.pdf. Acesso em: 22 ago. 2019.

LEE, Y; CHOI, Jaeho. A review of online course dropout research: Implications for practice and future research. Educational Technology Research and Development, v. 59, n. 5, p. 593618. 2011. Disponível em: https://www.researchgate.net/publication/227246914 A review of online course dropout $\mathrm{r}$ esearch Implications for practice and future research. Acesso em: 22 ago. 2019.

SOUSA, A. S. Q; MACIEL, C. E. EXPANSÃO DA EDUCAÇÃO SUPERIOR: PERMANÊNCIA E EVASÃO EM CURSOS DA UNIVERSIDADE ABERTA DO BRASIL. Educ. rev., Belo Horizonte, v. 32, n. 4, p. 175-204, dez. 2016. Disponível em: http://www.scielo.br/scielo.php?script=sci_arttext\&pid=S0102-

$46982016000400175 \& \operatorname{lng}=$ pt\&nrm=iso. Acesso em 22 ago. 2019. 